\title{
A Qualitative Study on HIV Risk Behaviors and Medical Needs of Sex Workers in a China/Myanmar Border Town
}

\author{
WILLIAM C.W. WONG, M.B., Ch.B. ${ }^{1}$ and WANG YILIN ${ }^{2}$
}

\begin{abstract}
Ruili is a small border town between China and Myanmar where drugs and commercial sex are common, and rates of sexually transmitted diseases (STDs) including HIV, are high. A qualitative study was carried out on 89 commercial sex workers there in 2001 to understand more about their HIV awareness, medical-seeking behaviors and needs. We found that the sex workers were young and the turnover rates were high. Contrary to common belief, many came from nearby villages or cities, but were probably reluctant to participate in organized activities. Their medical knowledge was very limited, often acquired from peers and selfmedication was common. The contraception they used was inappropriate and screening for cervical cancer was nonexistent. They were very stigma conscious. Condoms were purchased in small quantities when required and used only if the clients were agreeable. These findings have strong implications for the future planning of services and HIV/STD prevention.
\end{abstract}

\section{INTRODUCTION}

$\mathbf{R}$ uili is a small Chinese town in the western most part of Yunnan, surrounded by Myanmar (Burma) on three sides. It had the first reported case of HIV infection through intravenous drug use in China, and according to the Ruili Health Bureau, there have been 736 cases of HIV since 1989 with 250 deaths, 137 times above the national average. However, the actual number of HIV-infected people is likely to be much higher. The prevalence rates among injecting drug users in Ruili were higher than $70 \%$, and among a sentinel sex workers population the prevalence was as high as $11 \%$ in $2000 .^{1}$
In a population of 110,000 , there are more than 200 brothels with 1500 Chinese workers and another 500 Burmese workers on the street or in different set ups. Because of fierce competition for business and high turnover rates, these women are vulnerable to HIV infection and other sexually transmitted diseases (STDs), and are difficult to target for prevention. In surveys of prostitutes in China, condoms usage rates are $15 \%-30 \%$; usage largely depends on the willingness of the customer. ${ }^{2,3}$ Although there is strong evidence to suggest that the most successful means of preventing STD and HIV transmission are those targeted at sex workers and their clients, ${ }^{4}$ little is known regarding who the sex workers in China are,

\footnotetext{
${ }^{1}$ Department of Community and Family Medicine, School of Public Health, Prince of Wales Hospital, Chinese University of Hong Kong, Shatin, New Territories, Hong Kong.

${ }^{2}$ HIV Promotion Coordinator, Dehong County Women and Children Development Center, People's Republic of China.
} 
where they come from, or their medical-seeking behaviors and needs. A qualitative study was carried out between March and April 2001 to assess these issues.

\section{METHODS}

We conducted four semistructured focus group discussions and seven semistructured, in-depth interviews: two focus groups with Chinese sex workers, two with Burmese workers, and 7 "on-the-spot" interviews with Chinese sex workers. We visited the sex workers from brothels in two red-light districts and invited them to come to the focus groups. The interviews were done at brothels scattered in different parts of Ruili. Two moderators sat at opposite ends of the room where they could encourage quieter participants to voice their opinions. Another person was responsible for the comprehensive written record. The discussion was not audiotaped to instill a sense of security among the workers.

Initial discussions were broad; respondents were asked to talk about themselves and their work. Later, they were asked to consider issues related to their medical-seeking behaviors and what medical provisions they wanted (Table 1). Because we were interested in the reasons behind decisions made by individuals, this list served as a guide to what we could ask. In this paper, only information relevant to the aims of this paper is reported which may be helpful to people who plan future service for this group of people.

\section{RESULTS}

A total of 34 brothels were invited to participate in the focus groups. Forty-six persons representing 16 brothels, of whom 7 were brothel managers (all female) attended the two meetings. During two meetings we met with 12 and 9 Burmese workers at a community center; 5 persons attended these focus groups twice. Twenty-seven persons, in groups ranging from 1-7 persons at a time, were interviewed from 7 of the 15 brothels we visited randomly in different parts of the town. This provided a total of 89 workers in our sample. The participants
Table 1. Semistructured Areas to be Covered in Focus Group and Interviews With the Sex Workers

About the sex workers

Age

Hometowns

Working history in Ruili

About medical-seeking behaviors and HIV awareness

Any illnesses in the previous month and 3 months?

Where and when did they go?

Views on private versus public doctors and perception of quality of service

Circumstances which they would visit doctors?

Where do they get condoms and other medical supplies?

Use of condoms

Routes of HIV transmission and prevention

About the expectation of a medical service . . .

Targeting groups of the clinic

Range of services and equipment expected

Sex of doctors

Charges of the clinic

Ideal location

Opening hours

reflected a broad range of personal and geographical characteristics (Table 2).

The median age of the Burmese and Chinese workers was 19.4 and 22.6, respectively, and the youngest Burmese worker was 15 and the youngest Chinese worker was 17. Most came from Sichuan Province, which is a highly populated province north of Yunnan. However, when we visited them at work, we found the majority were Yunnanese, some from nearby villages or the city of Monshi, which was only 2 hours away. Only 9 of 59 (15.25\%) of the Chinese workers were from urban areas while the rest came from the rural areas.

\section{Why did they come to Ruili?}

Many of the Chinese girls came from the same villages. Usually, one girl arrived at Ruili first and encouraged their friends to go there. A common scenario was that they came because they heard comments like "Ruili is really free and open, and business is thriving here."

According to the two Shanghais, "Prostitution is strictly prohibited in Shanghai and anyone who gets caught twice will end up with a death penalty."

Brothels also face pressure from commercial sex clients to have new faces so that the sex workers have to move around to maintain their income. 
Table 2. Personal and Geographical Characteristics of the Interviewees

\begin{tabular}{|c|c|c|c|c|c|}
\hline & & $\begin{array}{l}\text { Chinese sex workers } \\
\text { No. of respondent }(\%)\end{array}$ & Time & $\begin{array}{l}\text { Burmese sex workers } \\
\text { No. of respondent }(\%)\end{array}$ & Time \\
\hline $\begin{array}{l}\text { Mean age } \\
<18 \\
19-21 \\
22-24 \\
25-27 \\
28-30 \\
>30\end{array}$ & & $\begin{aligned} & 59(80.82) \\
& 7(11.86) \\
& 17(28.81) \\
& 12(20.34) \\
& 11(18.64) \\
& 6(10.17) \\
& 4(6.76)\end{aligned}$ & 22.62 & $\begin{aligned} 16 & (100) \\
5 & (31.25) \\
8 & (50) \\
3 & (18.75) \\
0 & (0.00) \\
0 & (0.00) \\
0 & (0.00)\end{aligned}$ & 19.37 \\
\hline $\begin{array}{l}\text { Places of origin } \\
\text { Yunnan (\%): } \\
\text { Adjacent provinces (\%): } \\
\text { Other provinces (\%): }\end{array}$ & $\begin{array}{l}\text { Focus groups } \\
\text { Interviews } \\
\text { Focus groups } \\
\text { Interviews } \\
\text { Focus groups } \\
\text { Interviews }\end{array}$ & $\begin{aligned} 59 & (80.82) \\
3 & (5.08) \\
14 & (23.72) \\
25 & (42.37) \\
10 & (16.95) \\
4 & (6.78) \\
2 & (3.39)\end{aligned}$ & & $\mathrm{N} / \mathrm{A}$ & \\
\hline $\begin{array}{l}\text { Location } \\
\text { Countryside (\%) } \\
\text { Cities (\%) }\end{array}$ & & $\begin{array}{r}59(80.82) \\
50(84.75) \\
9(15.25)\end{array}$ & & $\begin{array}{l}16(100) \\
11(68.75) \\
5(31.25)\end{array}$ & \\
\hline $\begin{array}{l}\text { Turnover rate (days) } \\
\text { Range }\end{array}$ & & 71 (97.26) & $\begin{array}{c}24 \\
2 \text { day-1 year }\end{array}$ & $16(100)$ & $\begin{array}{c}40 \\
5 \text { days }-1 \text { year }\end{array}$ \\
\hline
\end{tabular}

Gang control among the Burmese workers was common, and girls were usually "imported" by an organized network. Three Burmese girls told us that they had been sold by their family to pay off debts, usually for a limited period but often on a repeated basis. Some came because they had wanted to escape from family conflicts or poor local working conditions.

\section{Medical-seeking behaviors of sex workers}

Stigmatization was a common concern and no sex workers wanted a clinic to serve them alone. They preferred going to government hospitals for serious treatment because the hospitals were perceived as more reliable and having higher standards. Technology and advanced equipment played an important role in their definition of good quality care. No one reported to have had any STD/gynecological symptoms over the previous 3 months but further questioning revealed that vaginal discharge, lower pelvic pain, and dyspareunia was common. No one in this sample had regular gynecology check-ups or Pap smears. The sex workers claimed that they did not mind the gender of the doctor, provided he was "patient, caring, and professional." Many asked for af- fordable and confidential access to HIV testing, although they knew the local antiepidemic station would provide such service. One brothel owner said,

One of my "girls" was told she was HIV positive in front of me and all the patients in the waiting area by the staff at the antiepidemic station. When asked what to do next, she was told there was nothing could be done and we were shown to the door."

The sex workers constantly worried about the quality of medicine used in private practice because there were many rumors regarding fake or poor quality drugs. However, they disliked bureaucracy in government clinics and worried about confidentiality. For example, one participant stated, "I have to register at the ground floor, see the doctor on the third floor, then went to pay on the second later, x-ray on the fifth and pharmacy on the ground floor again."

In terms of operating hours, the Chinese workers would prefer the clinic to open late and remain open until the early hours of the morning. They said:

We don't get up till late in the afternoon and find it too hot to get out in the early afternoons anyway. Hence, the most likely time to see a doctor was between 4-6 PM unless something unpleasant hap- 
pened during the night, in which case we would see a doctor first thing in the morning.

Many of the sex workers tried self-medication or private physicians first because they were perceived to be more user-friendly and provide more privacy. The sex workers commonly learned from each other, for example, a vaginal douche was used to "clean" their system. There were three workers (all from the same brothel) who taught each other to take antibiotics on a regular basis to "rid any STDs."

It is difficult to say what the appropriate fee for medical treatment is and the only guidance provided by participants was "reasonable" charge. Quite a few people complained about over-prescription of medications and cited it as a way for the private doctors to make money. Money was a lesser concern for the Chinese sex workers because they could earn enough or at least borrow from friends, while the Burmese workers said their manageress would pay if they got sick and deduct from their earnings later.

\section{Use of condoms}

Many sex workers did not know that HIV, a virus, caused AIDS, while some did not know that HIV could be transmitted vertically from mother to baby or by tattooing with unsterilized needles. A considerable number believed that sharing daily utensils and swimming in the same pool could transmit HIV. Regarding use of condoms, many did not know how to use them properly.

Both Chinese and Burmese workers usually bought small quantities of condoms (1 pack at a time) on an "as-needed" basis from local pharmacies. They had no knowledge of how to choose from different brands on the market, and cost rather than quality was their prime concern. Some Burmese workers said, "We will try to charge the customers extra for condoms but if the clients refuse, we will give in. Otherwise, our manageress will beat us up for being difficult."

As a result, the Burmese workers claimed that condoms were used less than half of the time. Burmese workers had an additional negotiation difficulty with their Chinese clients because of the language barrier. They wished to have more training in the Chinese language and in negotiation skills. Nearly half of the Chinese workers also did not use condoms with their partners or lovers. Most had an intrauterine device inserted for contraceptive purpose.

\section{DISCUSSION}

This study found that both Chinese and Burmese sex workers are young with the majority of the Chinese sex workers coming from the countryside or adjacent provinces. The average time that they stayed in Ruili was short. Some said their relocation resulted from peer information, high expectation of working condition, and local policies. Some Burmese workers were "sold" for financial reasons. Medicalseeking behaviors were limited by the workers knowledge and experience such as risk assessment in screening of cervical carcinoma, while others were influenced by rumors as in the choice of medical establishments. Self-medication and health advice from peers was common. The workers were very conscious of shame and social stigma, but were less concerned about the gender of the doctor. Condoms were bought when required and used only if the clients were agreeable.

Most studies of sexual behavior are confounded by two major methodological difficulties: biases in the selection of subjects and the reliability of the response. ${ }^{7}$ There was a risk that women willing to participate in focus group discussions or interviews are more likely to be a proactive and self-selected group. This was balanced by our outreach interviews. Another source of bias in this study is the unacceptability bias because of the highly sensitive nature of their business and the women themselves. Some women might not disclose their condom usage rate or tell us they had been to doctors, and therefore appear unhealthy to others in the same business. However, we obtained similar responses in both group discussions and individual interviews, and some of our findings such as high mobility and condom use agree with other research. 8,9

Chinese sex workers from Yunnan made up 
nearly a third of our sample, but a disproportionately small number of them participated in the focus groups compared to those we visited at work. It is commonly believed that sex workers tend to work away from home in order to avoid embarrassment and potential recognition. ${ }^{5}$ However, it is quite possible that local workers are just as prevalent but more reluctant to participate in any organized activities. Therefore, extra efforts and target-oriented approaches are required to ensure inclusion of this subgroup.

The turnover rate of sex workers is extremely high and hence development work with them is difficult. Despite our reassurance, a good proportion of the workers declined to reveal their identity and such fear of being found out might have attributed to their high mobility. This is made worse by a law that requires "any person liable to transmit AIDS" to be referred to the health service for HIV testing. ${ }^{6}$ The movement of these workers adds to concerns for potential increase in the sexual transmission of HIV and other STDs in China. ${ }^{7-9}$

It may be difficult for these young sex workers to grasp the significance of STD/HIV and the skills to negotiate condom use. They often acquired their health information and practices from their peers or manageress, which were inappropriate and at times could be harmful. Because they were very worried about shame and social stigmatization, such attitudes might deter them from seeking medical help and thus use an inappropriate form of contraception that may increase the risk of pelvic inflammatory disease. On the other hand, they said they did not mind the gender of their doctors, which was quite different from surveys of rural women. ${ }^{10}$ Sex education in sex workers in China is desperately needed and cosmetic training may provide a good incentive and entry point.

Because of concerns about their image or the potential negative impact on tourism and the economy, some Chinese local governments have reverted to severe penalties for commercial sex work, as in Shanghai. The effect of this approach is that the problem was pushed elsewhere instead of being resolved locally. As a result, some sex workers ended up working far from home with little support, or even on the street, which reduces their negotiating power. Expensive health care in China also discourages some from seeking treatment and encourages self-medication. Hence, it helps fuel the spread of the current HIV /STD epidemic. Some of these workers, especially the Burmese ones, have to work harder with less freedom in selecting their clients, in order to pay off their debt to the brothel owners. A sensitive but affordable health service is essential in controlling this epidemic.

\section{CONCLUSION}

There are layers of myths and curtains surrounding the sex trade in China, both from inside and outside the business. Until we make use of the information on demographic movements and behavioral patterns, and tailor better HIV /STD control and prevention programs for this high-risk group. The HIV epidemic will continue to be a major health threat in China.

\section{ACKNOWLEDGMENTS}

This work was made possible by a scholarship from the Royal College of General Practice, United Kingdom, and was presented at the WONCA Asia-Pacific conference at Kuala Lumpur, April 2002.

\section{REFERENCES}

1. UNAIDS Report on the Global HIV/AIDS Epidemic-Fact sheets: Asia Pacific Round up. 2002. Online document at: www.unaids.org/barcelona/ presskit/factsheets/Fsasiapacific en.doc (Assessed on July 23, 2002.

2. Chinese Ministry of Health, UN Theme Group on HIV / AIDS in China. China Responds to AIDS-HIV / AIDS Situation and Needs Assessment Report. Beijing: Chinese Ministry of Health 2002.

3. Lau J, Tsui HY, Siah PC, Zhang KL. A study in female sex workers in southern China (Shenzhen)-HIVrelated knowledge, condom use and STD history. AIDS Care 2002;14:219-233.

4. Larivee C, Lamptey P, Zeitz P, eds. Module 2: Technical strategies. In: Strategies for an Expanded and Comprehensive Response (ECR): A Handbook for Design- 
ing and Implementing HIV/AIDS Programs. Arlington, VA: Family Health International, 2002 pp. 21-44.

5. Gil VE, Wang MS, Anderson AF, Lin GM, Wu ZO. Prostitutes, prostitution and STD/HIV transmission in mainland China. Soc Sci Med 1996;42:141-152.

6. Anderson A. AIDS in China: A criminal justice perspective. Crim Justice J 1992;14:1.

7. Zhang K. Epidemiology of HIV in China. Beijing: PUMC Publishing House, 2000, pp. 1-4.

8. Cohen MS, Henderson GE, Aiello P, Zheng H. Successful eradication of sexually transmitted diseases in the People's republic of China: Implications for the 21st century. J Infect Dis 1996;174:223-229.

9. Liao SS. HIV in China: Epidemiology and risk factors. AIDS 1998;12(Suppl B):19-25.

10. Gareen IF, Greenland S, Morgenstern, H. Intrauterine devices and pelvic inflammatory disease: Metaanalyses of published studies, 1974-1990. Epidemiology 2000;11:589-597.
11. Zhang KN, Bingxian Q, Jing F, eds. A case study of women's needs in reproductive health in Yunnan. In: Reproductive Health Services and Relative Research. Beijing: People's Medical Publishing House, 1999, pp. 253-262.

Address reprint requests to: Dr. William Wong Department of Community and Family Medicine 4th Floor, School of Public Health Prince of Wales Hospital Chinese University of Hong Kong Shatin, New Territories Hong Kong

E-mail: freewillyw@hotmail.com 